\title{
Afetividade e poder entre os imigrantes brasileiros no Porto"
}

\author{
Igor José de Renó Machado**
}

\begin{abstract}
Resumo
$\mathrm{O}$ artigo trata da relação entre imigração brasileira na cidade do Porto e a constituição de relações de poder através do controle de ofertas de possíveis relacionamentos afetivos por alguns imigrantes brasileiros em condições de atuar como intermediários entre as redes familiares portuguesas a que têm acesso e os imigrantes homens e pobres sobre os quais têm alguma influência.
\end{abstract}

Palavras-chave: Emigração Brasileira, Relações Afetivas, Poder, Portugal.

\footnotetext{
* Recebido para publicação em abril de 2004, aceito em setembro de 2004.

** Professor da Universidade Federal de São Carlos, São Carlos-SP, Brasil e pesquisador do CEMI (Centro de Estudos de Migrações Internacionais, IFCHUnicamp).igorr@unicamp.br
}

cadernos pagu (23), julho-dezembro de 2004, pp.257-278. 
Igor José de Renó Machado

Affection and Power among Brazilian Immigrants in Oporto

\begin{abstract}
The article deals with the relation between Brazilian immigration in the city of Oporto, Portugal, and the constitution of power relations through the control of affective relationships. Such control is conducted by some Brazilian immigrants in conditions to act as brokers between Portuguese family nets and the poor immigrants on which they have some influence.
\end{abstract}

Key Words: Brazilian Migration, Affective Relations, Power,

Portugal. 
Neste artigo pretendo examinar a relação dos imigrantes pobres brasileiros homens na cidade do Porto com o que podemos chamar de "mercado da paquera". Ou seja, a forma como conhecem suas namoradas e companheiras num ambiente de migração marcado por uma presença maior de homens e pelo fato singular de que grande parte das mulheres brasileiras com as quais estes homens se relacionavam eram trabalhadoras do sexo. A situação que descrevo refere-se ao ano de 2000 e vale lembrar que a migração em Portugal é um fenômeno extremamente dinâmico. Tudo o que se refere à migração internacional em Portugal muda muito rápido, desde a constituição dos fluxos de imigração até a legislação que regula a entrada, permanência $e$ saída de estrangeiros.

A relação dos homens brasileiros pobres com o mercado da paquera é uma das dimensões da vida coletiva de uma certa "comunidade brasileira", que foi objeto de análise na minha tese de doutorado. ${ }^{1}$ Como parte de uma teia de relações mais abrangente, é preciso qualificá-la a partir de uma lógica inclusiva ${ }^{2}$ das relações destes imigrantes brasileiros. Para tanto, será preciso explicitar o eixo principal da organização social dessa "comunidade", o que chamei de "jogo da centralidade".

Jogo da centralidade

Chamo de "jogo da centralidade" a luta, entre brasileiros, para estabelecer diferenciações entre si. O "estar no mundo" de imigrantes brasileiros é marcado por uma aproximação com um

\footnotetext{
1 MACHADO, Igor José de Renó. Cárcere público: processos de exotização entre imigrantes brasileiros no Porto, Portugal. Tese de Doutorado, IFCH/Unicamp, 2003.

2 Ver ViveIROs DE CASTRO, Eduardo. Etnologia Brasileira. In MiCELI, S. (org.) $O$ que ler na ciência social brasileira (1970-1995). São Paulo/Brasília, Sumaré/ANPOCS/CAPES, 1999; O nativo relativo. Mana, Estudos de Antropologia Social, vol. 8, n 1, abril de 2002.
} 
"centro", num processo paralelo ao descrito por Geertz ${ }^{3}$ em Negara, onde a antiga corte balinesa legitimava-se por uma proximidade inventada que era fruto de disputas com a linha de descendência do grande herói real-mítico Majapahit. No caso dos brasileiros no Porto a luta é para se aproximar de uma imagem de identidade brasileira baseada na idéia estereotipada que vige em Portugal e que permite a existência de um lugar específico no mercado de trabalho para os brasileiros. A questão é quem é mais ou menos brasileiro.

O trabalho foi construído a partir do acompanhamento de uma rede de imigrantes pobres ${ }^{4}$ que ocupam determinados lugares no mercado de trabalho português, principalmente no que denomino "mercado da alegria" ${ }^{5} \mathrm{O}$ trabalho no mercado da

3 GeErTZ, Clifford. Negara, O Estado Teatro no Século XIX. Lisboa, Difel, 1980.

${ }^{4}$ Para análises sobre imigrantes brasileiros em outras condições sociais ver FELDMAN-BIANCO, Bela. Brazilians in Portugal, Portuguese in Brazil: constructions of sameness and difference. In: Identities Global Studies in Culture and Power vol. 8(4), 2001, pp.607-650; Entre a fortaleza da Europa e os laços afetivos da "irmandade" luso-brasileira: um drama familiar em um ato só. In: BASTOS, Cristiana; AlmeidA, M. V.; Feldman-BiAnCo, Bela, (coords.) Trânsitos coloniais: diálogos cruzados luso-brasileiros. Lisboa, Imprensa de Ciências Sociais, 2002; SANTOS, Gustavo. Sabiá em Portugal: a imaginação da nação na diáspora. Monografia de conclusão de graduação, Campinas, IFCH/Unicamp, 1996.

${ }^{5} \mathrm{O}$ trabalho de campo foi realizado entre março e setembro de 2000 e resultou na tese de doutorado (MACHADO, I. J. Cárcere Público..., Op.cit.). Sobre o perfil da população brasileira em Portugal, ver MACHADO, Fernando Luís. Contornos e especificidades da imigração em Portugal. Sociologia - Problemas e Práticas, $n^{\circ}$ 24, 1997, Partido Popular, pp.9-44; BAGANHA, M. I. A cada sul o seu norte: dinâmicas migratórias em Portugal. In: SANTOS, Boaventura de S. (org.) Globalização: fatalidade ou utopia? Porto, Edições Afrontamento, 2001; BaganHA, M. I. \& GoIs, P. Migrações internacionais de e para Portugal: o que sabemos e para onde vamos? Revista Crítica de Ciências Sociais, $n^{\circ}$ 52/53, nov. 1998/ fev.1999; BAGANHA, M. I. Migrações e Mercado de Trabalho: os Novos Desafios. Texto apresentado à Conferência A Europa, o desafio demográfico e o espaço de liberdade, segurança e justiça, 18 de Outubro de 2002, Centro Cultural de Belém, www.acime.gov.br em 15 de janeiro de 2003; BAGANHA, I. \& PEIXOTO, J. O estudo das migrações nacionais. In: FERREIRA et. alii. (orgs.) Entre a 
Igor José de Renó Machado

alegria se refere aos empregos que envolvem a animação (como músicos e dançarinos) e também o atendimento ao público (garçons, atendentes de comércio em geral). Incluo o atendimento ao público no "mercado da alegria" porque os empregadores portugueses pressupõem que, de alguma forma, os brasileiros são mais adequados para qualquer profissão que exija o trato com clientes, por conta da simpatia, cordialidade e alegria que esperam de qualquer brasileiro. $\mathrm{O}$ grande mercado de trabalho para mulheres brasileiras, no período do trabalho de campo, referia-se também e mais radicalmente, ao "mercado da alegria": laboravam como trabalhadoras do sexo e/ou trabalhadoras das casas de alterne. $^{6}$

O mercado de trabalho é fundamental na análise da construção da organização social dos brasileiros no Porto, como também na construção de identidades essencializadas referentes a imagens estereotipadas sobre o Brasil. ${ }^{7}$ Como um pressuposto básico para conseguir emprego é ter que se encaixar num modelo de "brasilidade" específico (ser alegre, comunicativo, submisso), esse exercício de subordinação a modelos simbólicos resulta em processos como o que pretendo analisar aqui. Ou seja, a determinação de um lugar no mercado de trabalho aos brasileiros

economia e a sociologia. Oeiras, Celta Editora, 1996. Em 2001, o número de brasileiros em situação legal em Portugal era de cerca de 50 mil imigrantes, segundo dados do SEF (Serviço de Estrangeiros e Fronteiras). Destes, cerca de $11 \%$ moravam no Porto. MACHADO, I. J. Cárcere Público... Op. cit., p.316.

${ }^{6}$ As casas de alterne são casas onde não se pressupõe a prostituição. $\mathrm{O}$ trabalho das mulheres é entreter os clientes e fazê-los consumir. Ganham comissão sobre o consumo e um pagamento por noite de trabalho. Embora a prostituição não faça parte deste trabalho, é sabido que as casas de alterne são também um lugar de contato para prostituição, que ocorre fora da esfera de interesses da casa de alterne.

7 Uma discussão sobre a origem e desenvolvimento dessas representações por parte da sociedade portuguesa é realizada em MACHADO, I. J. Cárcere Público... Op. cit. 
tem implicações tanto na organização da vida como na construção de identidades.

Neste contexto, o jogo da centralidade é uma constante avaliação, por cada imigrante, da sua própria centralidade em relação aos demais imigrantes. É um ato complexo de classificação que recorre a diferentes variáveis de classificação. Os brasileiros se aproximam ao "centro" da brasilidade por rotas diferentes. A diferenciação é um instrumento de poder que serve para distanciar os outros do centro das representações. A elaboração de fronteiras, simbólicas ou não, por parte de imigrantes não é um exercício de incluir-se num grupo, mas de excluir outros. Ou seja, os limites na aproximação a essa imagem central são impostos aos outros, na esperança de ser mais central por afastá-los. Para qualificar a centralidade, as imigrantes utilizam os termos "brasilidade" e "abrasileirar": ou seja, "abrasileira-se" aquele que consegue alguma legitimidade no sentido das determinações do "centro exemplar". O centro exemplar é a coleção de imagens estereotipadas sobre o Brasil (samba, futebol, sexualidade e mestiçagem) e que regem a conduta das pessoas envolvidas nesse processo. Vale lembrar que não existe um "abrasileiramento" absoluto, pois isto seria pressupor a existência de uma essência absoluta, o que não é minha opinião. Mantive os termos, entretanto, por considerar que a idéia geral de "abrasileiramento" é mais correta para explicar o processo de centralidade: de fato, os brasileiros buscam tornar-se mais brasileiros no sentido valorizado pelo jogo da centralidade. Adoto também esses termos por serem correntes entre os brasileiros; são termos nativos.

Vale lembrar que o jogo da centralidade envolve a dinâmica organização do cotidiano $e$ as disputas políticas entre os brasileiros no Porto. O prestígio e as posições de poder são centralizados por aqueles que ao menos aparentam ter a vida considerada, perante os demais brasileiros, como próxima ao modelo ideal. Este modelo corresponde a uma identidade pautada pela solidificação de imagens estereotipadas sobre a essência do brasileiro. Em suas 
Igor José de Renó Machado

ações, os brasileiros sempre procuram uma forma de construir para si mesmos alguma centralidade que seja reconhecida pelos demais.

Nos bares, alguns intermediadores ${ }^{8}$ assumem um lugar de prestígio, pois é através deles que um imigrante recente pode ingressar em alguma rede. Ingressar nessas redes pode significar um emprego melhor, oportunidades financeiras das mais variadas e, principal no que se refere a este artigo, um mercado de paquera diferenciado. Assim, a vida comunitária funciona como uma superposição de redes ${ }^{9}$ mediadas por intermediadores. A vida espacialmente dispersa ${ }^{10}$, aumenta a importância desses

\footnotetext{
8 Sobre intermediadores (brokers) ver principalmente a bibliografia sobre coronelismo e poder local, que analisa o papel desses personagens na construção de relações de poder. Ver, entre outros, FELDMAN-BIANCO, Bela. The Petty Supporters of a Stratified Order: The Economic Entrepreneurs of Matriz, São Paulo, Brazil (1887-1974). Tese, Phd em Antropologia, Nova York, Columbia University, 1981; CANIELlO, Márcio. Patronagem e Rivalidade. RBCS, $\mathrm{n}^{\circ} 14$, outubro de 1990; CARVAlHO, José Murilo de. Estudos de Poder Local no Brasil. Revista Brasileira de Estudos Políticos, nºs 25/26, julho de 1968/janeiro de 1969; Nunes LeAl, V. Coronelismo, Enxada e Voto. São Paulo, Alfa e Ômega, 1976; SILVERMAN, Sydel. Patronage and Comunity-Nation Relationships in Central Italy. Ethnology, $\mathrm{n}^{\circ}$ 4, 1977. Ver também a análise sobre imigrantes em lugares específicos de mediação como "intermediadores culturais", forma que adoto neste trabalho, como FELDMAN-BIANCO, Bela. A Saudade Portuguesa na América: Artefatos Visuais, Histórias Orais e a Tradução de Culturas. Horizontes Antropológicos, ano 1, $\mathrm{n}^{\circ}$ 2, Porto Alegre, UFRGS, 1995, pp.59-68; A (Re)construção da Nação Portuguesa e a Transnacionalização de Familias. Cadernos CERU, série 2, vol. 6, USP, 1995, pp.89-104; FELDMAN-BIANCO, Bela e HusE D. Entre a Saudade da Terra e a América: Memória Cultural, Trajetórias de Vida e (Re)construções de Identidade Feminina na Intersecção de culturas. Ler História, nº 27/28, ISCTE, Lisboa, 1995, pp.45-73.

9 Ver MAYER, Adrian. A Importância dos "Quase-grupos" no Estudo das Sociedades Complexas e BARNES, J. A. Redes sociais e processo político. In: Feldman-Bianco, Bela. (org.) Antropologia das Sociedades Contemporâneas. São Paulo, Global, 1987.

${ }^{10}$ Os imigrantes brasileiros não vivem em "guetos" e isso têm conseqüências importantes na organização da vida dos brasileiros como um todo. O universo privado de uma possível vida comunitária fica bastante limitado e a socialização
} 
intermediadores, pois não há como se inserir numa rede brasileira sem o seu intermédio. Como centro dos circuitos de prestação, são esses intermediadores que determinam os sentidos das prestações, controlando os eventos e os momentos rituais de convivência, uma vez que os churrascos podem ser vistos como um ritual de reforço dos laços sociais. As redes formadas por intermediadores eventualmente ligam-se entre si, por intermédio do contato entre alguns intermediadores amigos, constituindo redes mais amplas e eventos mais populosos.

$\mathrm{O}$ acesso às redes menores, que são as principais - pois sem participar delas o brasileiro estará "solto", sem amparo social $e$ coletivo - dá-se através dos bares, onde as pessoas que participam dessas redes se encontram, montando um jogo flexível de interligações. Há momentos (em geral em churrascos) onde as pessoas das redes se unem, montando redes maiores, sempre numa situação de acumulação de prestígio por parte de pessoaschave em cada rede. São esses intermediadores que controlam a vida social e dão o tom da "brasilidade" exotizada na vida cotidiana portuguesa. Como o trabalho da maioria está ligado às imagens essencializadas/estereotipadas do Brasil, os imigrantes procuram reforçar a sua autenticidade enquanto brasileiros, articulando o jogo de centralidades. Quanto "mais abrasileirados" aparentam ser, maior influência exercem entre os brasileiros $e$ ganham maior legitimidade entre os portugueses com os quais encontram-se em posição simbolicamente subordinada, já que os empregos são mais facilmente conquistados por aqueles que se submetem aos estereótipos.

Assim, controlar os circuitos de prestação em círculos cada vez mais amplos confere maior poder $e$ centralidade a determinadas pessoas, que impõem a sua própria forma de brasilidade, ampla e vazia o suficiente para abarcar qualquer um

do imigrante é feita predominantemente na vida pública, ou seja, nos bares brasileiros. 
Igor José de Renó Machado

que não fuja dos estereótipos de malandragem, hipersexualidade $e$ alegria. A forma com que essas características amplas são elaboradas varia conforme a origem e o universo cultural do intermediador em questão.

\section{Mercado da paquera}

É através de redes, portanto, que grande parte da vivência dos brasileiros acontece. Os circuitos de churrascos na casa das pessoas marcam o padrão de sociabilidade: a sua turma de churrasco é sua rede preferencial de relações, onde as prestações mais estreitas acontecem: ajudas mútuas, doação de presentes, empréstimos de dinheiro, oferecimento de empregos, abrigo nas casas, apoio emocional. Estes churrascos acontecem em qualquer ocasião, desde celebrações de aniversários até a pura e simples socialização. A organização é fácil e imediata, basta trocar alguns telefonemas, decidir o lugar, quem leva o quê e, em 30 minutos, está organizado o churrasco. Estes momentos são importantes por dar corpo a uma convivência entre os brasileiros fora dos lugares de trabalho e fora dos bares. Isto é crucial por um motivo principal: o mercado da "paquera".

Os churrascos propiciam encontros afetivos com mulheres portuguesas, pois em geral são realizados nas casas dos intermediadores de cada pequena rede que, por estarem há mais tempo em Portugal detêm um número maior de relações com portugueses. Isto provavelmente acontece pouco nos bares, por serem poucas as portuguesas que os freqüentam e tampouco acontece nos locais de trabalho onde há predominantemente homens brasileiros, como as churrascarias. Obviamente, há pessoas com mais sorte e menor dependência das redes, pessoas mais ou menos extrovertidas, com maior ou menor capacidade de se relacionar com mulheres portuguesas, mas os churrascos são os lugares mais relevantes para o mercado da "paquera".

Nos churrascos, verdadeiros potlachs brasileiros no Porto, trocam-se significados, bens e conhecem-se mulheres. Os 
significados são parte do aprendizado da vida em Portugal, mediado pela ajuda dos imigrantes mais velhos, os macetes, os "toques", ensinamentos valiosos de quem já cometeu muitos erros. Como se portar com os portugueses, como servir as mesas, o que significam as gírias, como tratar as mulheres, como lidar com os patrões, etc. A troca lingüística é fundamental na vida dos brasileiros, pois embora a língua seja a mesma, a língua falada no cotidiano é bastante diferente. Os brasileiros recém-chegados têm dificuldades em entender o modo de falar dos portugueses $e$ as inúmeras gírias. Estas têm usos muito elásticos, dando margens a trocadilhos, ironias, zombarias que os brasileiros não entendem e que, em geral, os colocam em situações de humilhação: são alguns comentários quando servem as mesas para fregueses portugueses, quando procuram os serviços públicos, principalmente o SEF, Serviço de Estrangeiros e Fronteiras, que é o responsável pelos processos de legalização, entre outras situações. Nos churrascos os recém-chegados escutam as mesmas gírias faladas agora pelos mais antigos e perguntam o que significam, aprendendo com as brincadeiras o amplo leque de significados das palavras. De posse de um arsenal mínimo de "galeguês" (como alguns chamam o falar português), os recémchegados enfrentam as situações do cotidiano com maior segurança, começam a dominar os códigos do falar português, entendem o que significam as entonações, etc.

É através dos intermediadores e das redes que visões sobre portugueses, brasileiros e sobre o Brasil e Portugal são formuladas e ganham as ruas. Os intermediadores têm o controle das palavras, do universo da comunicação: eles ditam as gírias, eles são os adaptadores do português falado por imigrantes brasileiros para o português falado em Portugal. É facilmente identificável um "sotaque" brasileiro específico dos imigrantes no Porto (não posso fazer afirmações sobre Portugal como um todo, já que a fala regional deve influenciar muito na produção de sotaques imigrantes). Esse falar é uma forma de socialização, pois inclui gírias portuguesas abrasileiradas, tonalidades que significam 
intenções variadas e expressões híbridas que têm sentido apenas para os brasileiros no Porto. O controle desse universo lingüístico é outra forma de promoção de circuitos de troca entre brasileiros, a ponto de ser possível identificar o tempo de imigração de alguém pelo sotaque, em outras palavras, quanto maior o sotaque brazuca, maior o tempo de imigração. O interessante é que até os portugueses percebem a transformação da fala do imigrante, pois são capazes de identificar os recém-chegados pela fala ainda bastante "fresca".

O churrasco opera como um drama que distensiona a vida cotidiana marcada por conflitos no local de trabalho, pelo racismo a que estão sujeitos e pela insegurança da ilegalidade. O churrasco como evento social tem significados múltiplos e, numa das dimensões, é um ritual de proteção coletiva, uma válvula de escape. Neste sentido é um lugar de aprendizado simbólico efetivo, onde recém-chegados descobrem tanto as sistemáticas opressões a que os brasileiros estão sujeitos, como as formas de desvio e resistência às mesmas situações. Aprendem argumentos que vão usar normalmente como se fossem seus, como as formas mais usuais de desculpas, as estratégias para contornar as broncas de chefes portugueses, ou como responder aos comentários desagradáveis que costumam ouvir.

Por outro lado, nessas redes formadas basicamente por homens ${ }^{11}$ brasileiros, a apresentação de mulheres é algo fundamental: como o mercado da paquera de mulheres brasileiras é desfavorável aos homens, a paquera acontece com mulheres portuguesas. Nesse momento, a intermediação de imigrantes mais antigos, em geral casados com mulheres portuguesas e com acesso a algumas redes familiares e de amizade portuguesas, é de

\footnotetext{
${ }^{11}$ As redes com as quais tive mais contato eram formadas por uma maioria de homens brasileiros. Havia poucas mulheres brasileiras nessas redes. A maior parte das mulheres brasileiras que freqüentavam os mesmos bares onde a maior parte da pesquisa foi realizada eram trabalhadoras do sexo, e apenas poucas delas participavam das redes.
} 
imenso valor. São os intermediadores que funcionam como agentes matrimoniais, o que os coloca numa posição de grande importância dentro do grupo.

Assim, um grande número dos homens que fazem parte da rede da qual mais participei estava casado ou namorava alguma mulher portuguesa. Isto acontece acentuadamente com os imigrantes mais veteranos, que conviveram com uma situação mais desfavorável em relação às mulheres brasileiras que os imigrantes mais recentes. Entre os veteranos é mais difícil um casal de brasileiros do que entre os "calouros". Mas isto não muda o fato de que, de qualquer forma, permitir o acesso a redes familiares ou de amizade portuguesas é uma forma de poder. Em Portugal, de certo modo, casar com um homem brasileiro não é de mau tom, tendo em vista que em geral eles estão em melhor situação econômica do que as suas futuras esposas portuguesas. Ou seja, embora os brasileiros estejam num lugar desprivilegiado na estrutura social portuguesa, há portugueses em situação semelhante ou pior. Não se pode esquecer que Portugal continua sendo um país de emigração e que muitos portugueses das classes baixas procuram trabalhos sazonais nos países mais ricos da União Européia.

Mas há diferenciações temporais que indicam que essa possibilidade de casamento com portuguesas era mais fácil no passado recente e que imigrantes recém-chegados encontram um racismo mais consistente contra brasileiros que dificulta os relacionamentos binacionais. Talvez aqui a retórica dos "bons tempos que não voltam nunca mais" seja um indicador de um processo de perda de prestígio dos brasileiros na sociedade portuguesa. Anteriormente, segundo os lamentos, era incrivelmente fácil arranjar companheiras portuguesas, que estariam predispostas a encontros amorosos com os brasileiros devido à "fama" e "prestígio" destes em Portugal. Lembremos que a sexualidade portuguesa está atravessada pela imagem do brasileiro como hiper-sexualizado. 
Igor José de Renó Machado

\section{As trabalhadoras do sexo}

Em termos de relações de amizade, o circuito das trabalhadoras do sexo, às vezes, coincide com o dos homens, mas sempre numa perspectiva de distância em termos de relacionamentos amorosos. Há um acordo mútuo: a arraigada cultura machista dos homens brasileiros leva-os a não quererem casar com trabalhadoras do sexo e estas, por sua vez, também não querem se casar com brasileiros, por razões que explico a seguir. As trabalhadoras do sexo freqüentam os bares brasileiros e eventualmente churrascos organizados pelos participantes das redes, mas estão em geral mais interessadas em casar com um português. É a forma de "sair da vida" e conseguir a legalização em Portugal, uma vez que estão, em sua grande maioria, em situação de ilegalidade. Mas quando isso acontece, as mulheres são intimadas por seus novos maridos a cortar relações com os brasileiros, pois este contato, independente da prostituição, é visto como uma recaída moral. Ou seja, uma das condições da incorporação de ex-trabalhadoras do sexo em redes familiares portuguesas é o corte completo com a comunidade brasileira.

A primeira constatação é que as trabalhadoras do sexo brasileiras em Portugal são um assunto sério. Uma passagem pelos bordéis do Porto já denuncia o porquê dessa situação. Nos que visitei, cerca de oitenta por cento das trabalhadoras do sexo eram brasileiras. Havia trabalhadoras do sexo de vários lugares, muitas agora também vinham dos países da ex-União Soviética, dos PALOP, mas as brasileiras eram a preferência no gosto português.

É preciso diferenciar as casas de alterne das de "saída"; as primeiras são locais onde as moças são contratadas para seduzir os clientes com shows de strip-tease, bem como entretê-los como acompanhantes. Elas não são obrigadas a se prostituírem, embora algumas façam programas com clientes. As funcionárias devem ainda estimular os clientes a consumir o máximo. Em outras palavras, nos alternes elas podem ou não ser trabalhadoras do sexo. Já as casas de "saída" são locais onde o objetivo é 
unicamente fazer os programas, ou seja, "sair" com o cliente. As casas de alterne são caras e o trabalho é entreter e seduzir os clientes, fazendo com que gastem muito dinheiro em bebidas. As casas de alterne chiques contratam muitas brasileiras que, por falarem português, facilitam a aproximação e a conversação. Mas a presença das brasileiras deve-se principalmente à idéia de que brasileiros em geral são mais descontraídos, atirados e simpáticos. Em função disso, pelo que pude constatar, é preciso haver brasileiras nesses lugares.

A presença das trabalhadoras do sexo brasileiras na vida noturna dos bares brasileiros é, de qualquer forma, intensa, pois muitas delas preferem passar as noites de folga nas casas brasileiras. São as noites de domingo e um pouco as de segunda, onde se encontram as trabalhadoras do sexo em pequenos grupos, sempre assediadas pelos brasileiros. Uma das falas de um dos entrevistados nos ajuda a visualizar esta situação:

A primeira vez que eu cheguei na noite aqui no Porto, num bar de música brasileira, chamava-se Aconchego, há quase cinco anos atrás... e cheguei no Aconchego... não sei, nós chegamos, éramos quase cinco, o meu irmão estava aqui também, o meu irmão veio passar aqui um mês de férias, o meu irmão foi conosco, éramos quatro ou cinco, e tinham umas mulheres que ficaram olhando pra gente. Porque aqui, nos bares de música brasileira, ainda tem essa coisa que vão muitas prostitutas.

- Brasileiras?

- Brasileiras. E não só. Hoje em dia não tanto, mas na época eram... a maioria das prostitutas brasileiras estava sempre nesses bares. Sábado a partir das três da manhã era certo elas estarem lá, e no domingo a partir da meia-noite elas estavam sempre presentes. E veio um cara e... eu achei estranho porque tinha muita gente olhando pra nós. Até que veio um cara e veio falar comigo: "Olha, cuidado com essas mulheres que tem vagabundo que, entre aspas, são os donos delas e já estão de olho em vocês. Cuidado pra não 
Igor José de Renó Machado

arranjar confusão. Então foi logo a primeira experiência que eu tive em bar de música brasileira aqui”.

As feições das brasileiras da vida noturna são as mais variáveis e elas vêm de todos os lugares do país, embora boa parte delas assuma-se como carioca. É evidente que ser do Rio de Janeiro confere mais status às trabalhadoras do sexo brasileiras entre os clientes portugueses, mostrando que o jogo da centralidade é influenciado também pela percepção que o português tem da autenticidade brasileira, ou seja, a imagem que o Rio de Janeiro representa mais o Brasil que outras localidades.

Há uma posição de destaque assumida por algumas extrabalhadoras do sexo entre os imigrantes brasileiros: é a de dona de bar brasileiro no Porto. Das poucas casas voltadas para o público brasileiro no Porto em $2000^{12}$, duas eram controladas por ex-trabalhadoras do sexo casadas com portugueses que, ao contrário do processo habitual de retirá-las dos meios brasileiros, procuraram incentivar e ganhar algum dinheiro com a história pessoal das esposas. Os seus bares estavam sempre cheios, pois elas conheciam muita gente e tinham muitos contatos depois de alguns anos de prostituição em Portugal. Essas duas mulheres assumiram lugares de destaque no jogo da centralidade, pois têm grande capacidade de brasilidade. Como os músicos e jogadores de futebol, são vistas como embaixadoras de uma brasilidade profunda, baseada na imagem da sexualidade agressiva e sensual. Uma vez que passaram também a controlar empregos e redes familiares portuguesas, começaram a ter bastante influência entre os brasileiros. As más línguas juraram-me que elas também

\footnotetext{
${ }^{12}$ Quando retornei ao Porto em 2002, a principal diferença no ambiente da noite brasileira era a profissionalização dos bares para brasileiros. Se em 2000 estes bares eram pequenos e controlados por pequenos comerciantes, em 2002 os grandes empresários da noite estavam investindo neste mercado e já existia uma grande casa voltada basicamente para brasileiros. Isto indica o crescimento e a institucionalização da presença de imigração brasileira no Porto.
} 
estavam envolvidas no trabalho de aliciamento de trabalhadoras do sexo no Brasil, o que, obviamente, não pude confirmar.

Para que se tenha uma idéia mais clara da grande quantidade de trabalhadoras do sexo brasileiras em Portugal, uma reportagem de Sandra Cohen, do jornal O Globo, de 30101993, anunciava que numa noite de busca, o Serviço de Estrangeiros e Fronteiras (SEF) havia prendido no Porto e em Lisboa 111 trabalhadoras do sexo imigrantes em situação de ilegalidade. Destas, 103 eram brasileiras. Esta rede que foi aparentemente desmantelada havia levado, apenas em 1993, cerca de 1000 trabalhadoras do sexo brasileiras para Portugal. A reportagem indicava que havia, na época, mais três ou quatro redes como essa. Se em apenas uma noite de operação o SEF prendeu 103 trabalhadoras do sexo brasileiras, imagine-se quão fácil é encontrá-las. O fato de mais de $90 \%$ das presas naquela noite serem brasileiras indica, a meu ver, a preferência por elas e a ativação de redes sistemáticas de imigração clandestina especializadas em trazê-las. Segundo outra reportagem, esta da revista Focus (n. ${ }^{\circ}$ 101, 2001), 90\% das trabalhadoras das casas de alterne são estrangeiras, a grande maioria em situação ilegal. Deste número, uma grande parte é composta por brasileiras, embora a quantidade de trabalhadoras do sexo vindas do leste europeu também venha crescendo nos últimos anos. ${ }^{13}$

\section{$\mathrm{O}$ controle da paquera}

Dado o panorama geral da imigração brasileira no Porto e a constatação da importância do jogo da centralidade, vejamos mais atentamente o mercado da paquera. Entre os brasileiros, a idéia da simpatia natural do brasileiro é um fator importante para conferir centralidade. Ou seja, aqueles mais simpáticos são

\footnotetext{
${ }^{13}$ Esses são os números apresentados pela imprensa, que podem ser (e muitas vezes são) exagerados. Os artigos são citados como uma referência sobre a presença das trabalhadoras do sexo brasileiras.
} 
considerados mais brasileiros e conseguem algum destaque nas redes locais de disputa por prestígio. A simpatia é amplamente associada à relação com mulheres $e$, no caso do cenário da migração no Porto, às mulheres portuguesas, consideradas como aquelas que podem realmente virar companheiras. De fato, as brasileiras trabalhadoras do sexo são desejadas para relacionamentos passageiros e não para possíveis casamentos.

A relação com as mulheres portuguesas é um dos elementos que possibilita a acumulação de centralidade, é um capital social ${ }^{14}$ valorizado. A forma mais eficiente de se relacionar com mulheres portuguesas era predominantemente através da inserção numa rede familiar portuguesa. O processo favorece os intermediadores, em geral há mais tempo em Portugal, pois eles tiveram muitas oportunidades de montar redes de relação entre portugueses, e muitos casaram-se com portuguesas que não participavam de redes. Estes "contatos iniciais" com redes familiares portuguesas aconteceram mais ou menos naturalmente para os intermediários, muitos deles em Portugal há mais de 15 anos. Mas uma vez inseridos em ciclos de relações inacessíveis para os imigrantes mais recentes, os intermediários podem "capitalizá-los" no jogo da centralidade.

Essa capitalização acontece em duas frentes distintas: a primeira é a que envolve o prestígio conferido a quem circula por entre várias redes e é visto como genuinamente brasileiro por exercer a simpatia "militantemente". A realização da simpatia $e$ cordialidade pelas redes de relacionamento representa mais centralidade a quem a executa. Como a percepção de brasilidade que rege o jogo da centralidade pressupõe a simpatia em todos os níveis de relação, não adianta nada apenas circular entre redes familiares portuguesas: é preciso trazer brasileiros para perto delas, como grande prestadores. É preciso, portanto, operacionalizar o acesso às redes de forma que mais brasileiros circulem por elas. É

${ }^{14}$ Bourdieu, Pierre. O poder simbólico. Lisboa, Difel, 1989. 
este movimento, regido por regras do jogo da centralidade, que transforma os principais intermediários em controladores do "mercado da paquera".

Pode-se entender como o controle (mesmo que parcial $e$ limitado) das oportunidades de apresentar mulheres portuguesas para homens brasileiros é uma arma política dentro da "comunidade brasileira" no Porto. Isso indica, por outro lado, que a experiência da imigração vai muito além da experiência do mercado de trabalho: quase tão importante quanto o trabalho, a vida afetiva num ambiente tão difícil é fundamental para o bemestar dos brasileiros. Por razões como esta, o controle do mercado da paquera pode conferir tanto prestígio como o controle do mercado de trabalho. Mas o mecanismo que rege este "controle" é similar nos dois campos: pode ser entendido a partir do jogo da centralidade e de uma certa imagem do brasileiro construída em relação com os estereótipos vigentes em Portugal $e$ aqueles produzidos pelo discurso nacional brasileiro. O mecanismo é marcado menos pelo controle rígido das oportunidades de trabalho e/ou paquera e mais pela capacidade de distribuir competentemente estas oportunidades.

Esta distribuição dever ser o mais pública possível, a fim de que se saiba que o intermediador $Y$ apresentou a nova namorada do brasileiro $\mathrm{X}$, assim como também é publico o oferecimento de um contato especial para que o brasileiro $\mathrm{Z}$ conseguisse emprego. Este ato constante de distribuição das oportunidades, afetivas ou profissionais, é parte de um ethos brasileiro na cidade do Porto, e acaba regulando a vida da comunidade. No caso específico do mercado da paquera, esse movimento de distribuição de oportunidades cria vínculos muito duradouros entre intermediários e aqueles que são ajudados. Obviamente, quando relacionamentos se estabelecem entre brasileiros $e$ portuguesas que fazem parte das redes familiares dos intermediários, os "incorporados" passam a fazer parte desta rede. Como detentores das chaves que abrem o campo social de 
imigrantes que não têm muitos contatos com famílias portuguesas, estes intermediários têm grande influência.

Uma vez inserido numa rede familiar portuguesa, o brasileiro passa a ter acesso a inúmeras oportunidades que lhe eram estranhas. Ele tem acesso a mais conhecimento sobre a vida portuguesa, sobre as oportunidades de melhorar de vida (como o acesso a financiamentos, por exemplo), sobre as formas de comportamento dos portugueses, na maioria das vezes indecifráveis para estes imigrantes. Têm acesso aos conhecidos de sua companheira, que podem oferecer oportunidades diferenciadas. Enfim, abre-se um novo mundo que pode significar uma qualidade de vida melhor. É claro que as experiências variam imensamente e uma variável crucial é ser aceito ou não pela família portuguesa da companheira. Quando isto não acontece, tudo torna-se mais difícil. Mas o fato é que, em geral, as redes familiares que os intermediários "controlam" são já mais abertas à presença de brasileiros, pelo simples fato de já contar com brasileiros em sua estrutura. $\mathrm{O}$ fato é que a ação distributiva dos intermediários criava, de certa forma, um universo de relações binacionais mais estreito.

A publicidade que os atos de apresentação de futuras cônjuges exige é satisfeita no espaço do churrasco, espaço no qual transitam muitos brasileiros que vêem e contam o que acontece. Os churrascos garantem a publicidade dos atos de prestação $e$ garantem os efeitos de centralidade que tais atos acarretam. Percebe-se aqui um pouco mais da importância desses churrascos na vida coletiva brasileira no Porto. São momentos rituais da movimentação das prestações e de reconhecimento que tais atos conferem. O resultado, em termos de mercado da paquera, é que os intermediários tornam-se espécies de parentes de um grande número de brasileiros, imediatamente "devedores". Tornam-se padrinhos de relações amorosas, estabelecendo relações hierárquicas. 
Igor José de Renó Machado

\section{Comentários finais}

Procurei demonstrar que a construção de um espaço eficaz de relações afetivas entre imigrantes brasileiros homens no Porto passa pela gramática das lutas por poder entre os membros da "comunidade brasileira" nesta cidade. ${ }^{15}$ Ou seja, a estruturação de um sistema de disputas entre intermediários engloba, como um dos elementos de acumulação de prestígio e capital social, o controle e distribuição de "oportunidades afetivas". Chamei de jogo da centralidade o mecanismo de disputas políticas, baseado num modelo ideal de brasilidade que deve ser perseguido por todos. Só os "mais" brasileiros têm lugares de destaque no cenário político. Esta imagem ideal é uma construção essencializada alimentada pelos estereótipos da sociedade portuguesa sobre o que é o Brasil e o universo de representações portuguesas sobre o Brasil acaba por delimitar aos brasileiros um lugar específico no mercado de trabalho, que é o que chamo de mercado da alegria.

O processo de enquadramento aos estereótipos acabou por se tornar uma forma de sustento econômico, reforçando sistematicamente os próprios estereótipos. Este é um processo de subordinação ativa, ou seja, não passivo. Os brasileiros executam uma política cotidiana de subordinação a uma imagem estereotipada da identidade brasileira, porque isso se tornou o centro ativo das disputas políticas entre os imigrantes. ${ }^{16}$ No que

\footnotetext{
${ }^{15}$ Uma discussão sobre a existência ou não de uma comunidade brasileira no Porto é realizada na minha tese de doutorado (MACHADO, I. J. Cárcere Público... Op. cit.). Chego à conclusão que ela existe, embora do ponto de vista dos imigrantes brasileiros esta existência seja sempre colocada em cheque.

${ }^{16}$ Algumas explicações sobre a origem e razão desta subordinação ativa são elaboradas em MACHADO, I. J. Cárcere Público..., Op. cit. A principal questão levantada foi um processo de inversão racial: a imagem essencializada da identidade brasileira em Portugal resulta num lugar privilegiado aos brasileiros negros e mulatos, que se encaixam melhor nos estereótipos. Não é por menos que os principais intermediários são mulatos: eles podem experimentar uma situação vantajosa em relação aos mecanismos de discriminação racial no Brasil.
} 
tange aos relacionamentos afetivos, este processo de aproximação ao centro, à imagem essencializada de uma suposta identidade brasileira tropical, resultou num sistema social de distribuição interessada de oportunidades amorosas. Partindo do princípio de que a simpatia é uma das características principais do autêntico brasileiro - portanto capaz de trazer capital social a quem a possui -, a capacidade de circular por redes familiares portuguesas $e$ apresentar possíveis cônjuges portuguesas a imigrantes "desamparados" resulta num mecanismo político de "abrasileiramento". Isto é, aqueles que dominam essas oportunidades tornam-se mais próximos da imagem ideal da identidade brasileira e acumulam mais capital social.

Esse processo desenvolvia-se num momento em que a distribuição entre homens e mulheres na composição do perfil do mercado da paquera era desfavorável aos homens: um desequilibrio numérico entre imigrantes brasileiros pobres homens e mulheres brasileiras "elegíveis" para o namoro, além de um forte preconceito contra os relacionamentos amorosos com trabalhadoras do sexo. ${ }^{17} \mathrm{O}$ resultado deste panorama foi uma dependência dos homens imigrantes em relação às redes para o acesso a oportunidades afetivas, dependência esta que era cuidadosamente explorada pelos intermediários brasileiros no Porto, gerando capital social para os controladores do mercado da paquera. Lembremos que as coisas podem mudar rapidamente

Executam o jogo da centralidade, portanto, como uma subordinação ativa que os "empodera".

${ }^{17}$ Os números do SEF sobre a legalização de brasileiros ilegais, realizadas por mudanças na legislação portuguesa de 2001, indicam uma proporção similar entre homens e mulheres em 2002: 12563 homens e 12301 mulheres conseguiram a autorização de permanência neste ano. Em 2001, 12087 homens e 11352 mulheres. Em 2000, 11652 homens e 10570 mulheres brasileiras eram residentes. Ou seja, o desequilíbrio entre homens e mulheres no que se refere ao mercado da paquera explica-se por padrões morais e não por desigualdades numéricas. Dados do SEF, retirados do site oficial www.sef.pt em 15/03/2004. Dados de 2002 provisórios (relativos a contabilizações de 14/05/2003). 
Igor José de Renó Machado

num cenário tão dinâmico quanto o da migração internacional em Portugal, mas o fato é que em 2000 esta era a ordem das coisas. 